as rapid and thorough as if it had been given in the ordinary way.

I will conclude by mentioning one case, not an exception, but a type of many others, in which the rectal injection of polyvalent anti-streptococcus serum gave a rapid result in a case of chronic gonorrhceal infection. A man, aged 28 years, came to the out-patient department of the hospital suffering from pains in several joints and especially of severe pain in the heel. He had been infected with gonorrbod some months previously and still had a slight urethral discharge. I injected 25 cubic centimetres of polyvalent anti-strepto. coccus serum per rectum and prescribed no other treatment He went home and when I saw him the following week all his symptoms had gone and there was no visible urethral discharge. He informed me that the pain in the heel, which was his chief trouble, went away within 24 hours after the injection. I should have mentioned that the patient had been under treatment elsewhere for three weeks before he consulted me.

The technique of the injections is extremely simple. It is not necessary to give a cleansing enema without there is much constipation. The patient lies on the left side on a couch and a No. 6 Jacques catheter is passed as far as possible into the rectum; to the catheter is attached the barrel of a glass urethral syringe into which the serum is poured; as a rule gravity is sufficient, but if the fluid does not flow readily the piston can be used in the ordinary way. After the injection the patient should be kept lying on the couch for a quarter of an hour and then can be sent home in a vehicle. Rest in bed is not necessary after the injection, but exertion should not be allowed.

Wimpole-street, $\mathrm{W}$.

\section{Clinitall a}

\section{MEDICAL, SURGICAL, OBSTETRICAL, AND} THERAPEUTICAL.

\section{A CASE OF POISONING BY BROMIDE OF POTASSIUM}

By A. OAMPBell Stark, M.B., B.S. Lond., LATE DEMOXSTRATOR ON MATERIA MEDICA AT ST. GEORGE'S HOSPITAL MEDICAL SCHOOL.

Porsoning by bromide of potassium is of sufficiently rare occurrence to make any well-marked example of it worth recording. The following case also presents some features of peculiar interest. The subject was a woman, aged 35 years. She was nearly nine months pregnant. She was of a neurotic temperament but otherwise perfectly healthy. She had suffered from facial neuralgia and was ordered one evening a six-ounce mixture containing 30 grains of bromide of potassium in the ounce. This she placed under her pillow and helped herself to at short intervals during the night. It was afterwards found that she had a private store of the drug which she also took, so that she swallowed altogether about four and a half drachms of the salt in less than 12 hours. When seen on the following day she was in a very drowsy and semi-comatose condition. She could be aroused by speaking loudly to her and answered -apparently without understanding the question-in a hesitating and tremulous manner but was unable to express herself intelligently on account of aphasia. This was extremely well marked and but for the history and the absence of other symptoms would have strongly suggested a cerebral lesion. Thus the medicine was referred to as soup, pastry, as cushion, and so on. She seemed conscious that she was using the wrong word and after several repetitions of it would relapse into silence. Left to herself she passed at once into a semi-comatose state. The respirations were deep, regular, and slightly stertorous, but not slower than normal. The pupils were normal in size and reacted well to light and to accommodation. The pulse was 76 , quite regular, and of good volume and tension. The foetal heart could be heard quite plainly. The knee-jerks were exaggerated and although the muscular movements were slow and feeble the patient was able to leave her bed without assistance and totter about the room. There was no anæsthesia of the skin or mucous membranes and she took food readily and with apparent appetite. These conditions continued without any change for two days. On the third day the aphasia had begun to disappear and by the end of the fourth day the patient was practically well. She had no recollection of what had happened during the first two days. No treatment was adopted except the administration of five-minim doses of liquor strychninæ every four hours. Three weeks afterwards the patient gave birth to a vigorous male infant, the labour being rapid and uneventful.

The case is instructive on account of the well-marked aphasia and the fact that labour and the foetus were quite unaffected by the drug. The aphasia is difficult to account for. Unless one assumes some specific action by bromide of potassium upon the cells or blood-supply of the vocal word centre one can only suppose it to be due to the general depression of the subcortical cells comparable to the temporary aphasia produced by exhaustion and debility.

Wanstead Park, Essex.

\section{A CASE OF " CEDEMA" LIMITED TO THE ARMS,} FACE, AND NECK. ? CAUSE.

By J. M. Bennion, M.A., M.D., B.O. Oantab.,

$$
\text { M.R.C.S. ENG. }
$$

THE patient, a married man, aged 40 years, was a painter by trade. His family history and his health previously to the present illness were satisfactory. On Nov. 4th, 1907, he came to my surgery complaining of pains in both thighs and forearms, which apparently were in the muscles. I gave him a mixture containing 15 grains each of sodium salicylate and potassium bicarbonate three times a day. One week later he consulted me about his arms being "swollen." On inspection both forearms were noted full and rounded. The skin was neither reddened nor hot. There was marked pitting on pressure on the dorsal aspects. The cedema was located to the posterior surface and the upper half of each forearm. On the backs of either hand were a few chilblains but no open wounds. The legs, feet, and the rest of the body were free from cdema. The patient was advised to give up work temporarily. The arms were massaged and he was ordered a mixture containing five minims each of nux vomica and Fowler's solntion. By Nov. 20th the cedema of the left forearm had disappeared and that of the right was less marked. On the 22nd some swelling of the lids of the left eye was noticed. The lids of both eyes were very odematous on the 24th. A few red blotches on the cheeks were also observed. The temperature and pulse were normal and remained so throughout the illness.

On Nov. 25th I asked my partner, Mr. T. W. Bailey, to see the patient with me. He was unable to find a cause for the man's condition and suggested his taking a mixture of iodide and mercury. On the $26 \mathrm{ih}$ the odema of the eyelids was less but it had spread over both cheeks. The patient complained of tenderness on pressure over both sternomastoid muscles and down the back of the neck. The voice was a little husky. He was put on a mixture containing 15 minims of liquor hydrargyri perchloridi and three grains of potassium iodide thrice daily. On the 27th the clema of the face was less evident. The skin over both mastoid bones and sterno-mastoid muscles was slightly red and pitted a little on pressure. EEjema of the left forearm had reappeared. On the 28th the neck was more swollen and the voice was almost gone. The uvula and fancial pillars were injected and swollen. Both forearms were œJematons.

By Dec. 1st the patient, who had been in bed during the previous week, was better. The cedema of the eyelids, face, and neck had cleared up. The voice was less hoarse. The doses of mercury and iodide were increased to 30 minims and tive grains respectively. On the 4th the patient felt quite well. The voice had quite returned. There was still slight œ Jema of both forearms. He was allowed out of doors on the 10th and no sign of cedema of either forearm was present after the 13th. The patient resumed his work early in January and has kept quite well up to the present time (April 18th)

The appearance of cedema in a patient is usually an important physical sign giving a clue to the nature of the disease. In the case described a careful examination of the man revealed no cause for his condition. The heart was sound and the urine was free from albumin. No evidence of thrombosis of any veins of the arms or elsewhere could be found. Angio-neurotic odema ${ }^{1}$ was considered as a possible explanation. But the history and clinical features of the 
case, whlch differed in so many details from the ordinary description of this rare disease, certainly did not confirm this bypothesis. The man's occupation threw no light on his condition. I might also add that there was no history of lead colic and no symptom suggestive of lead or any other chemical poison. The chilblains from which the patient had suffered in winter time before could not be the cause of the "cedema."

The fons et origo of the patient's illness is difficult to fathom. As a possible solution of the problem of diagnosis I should be inclined to suggest that the "cedema" was due to some disturbance of the normal vaso-motor mechanism. As regards the drug treatment of the case the mixture of iodide and mercury seemed to have some beneficial effect.

St. Mary Cray.

\section{A CASE OF SUBCLAVICULAR DISLOCATION OF THE} HUMERUS.

By William Bourne Hallowhs, L.R.C.P., L.M. L.R.C.S. IREL.,

SENIOR SURGEON, NEWARK HOSPITAL; CERTIFYIYG FACTORY SURGEON, NEWARK DISTRICT ; MEDICAL OFFICER TO THE POB'T OFFICE.

THE rarity of the above injury is my reason for placing it on record.

The patient, a burly Scotsman, about 15 stones in weight, came to see me one evening some few months ago stating that he thought his right shoulder "was out." He told me that on the same afternoon he was riding in a tram at Lincoln, when suddenly discovering that he was being taken farther than he wanted to go he jumped up and left the car while it was going rapidly; at the time he was carrying two parcels on his left arm. He said that he was thrown violently forwards but was unable to state accurately how his right hand came in contact with the ground. However, a lacerated wound over the thenar eminence seemed to indicate that, owing to the impetus given to him by the car, his right arm as he fell was extended in an outward and backward direction when his hand struck the ground. On removing his clothes a glance sufficed to verify his diagnosis, extreme flattening of the deltoid, marked prominence of the acromion, and a deep sulcus over the glenoid cavity (into which three or four fingers could be pressed with ease) indicating the absence of the head of the humerus from its normal position. Closer investigation and palpation revealed the fact that the head of the humerus was not in the axilla, neither could it be felt by careful examination in that region. A globular swelling situated below the middle and outer third of the clavicle, the shaft of the humerus pointing in the most marked manner outwards and somewhat backwards, and complete inability to approximate the elbow to the side, proved beyond doubt that the case was one of those so rarely met with-viz., complete subclavicular dislocation of the humerus.

Placing the patient flat on his back and flexing the elbowjoint I firmly gripped the lower end of the humerus and applied extension downwards, my object being to clear the coracoid when the time came for employing rotation outwards. After a few minutes' extension, gradually applied with increasing strength, the globular swelling had considerably moved downwards from its position immediately below the clavicle; then suddenly rotating outwards, followed instantly by bringing the arm sharply across the chest, I had the satisfaction, at the second attempt, of feeling and hearing the head of the bone slip back into its normal position. Considerable swelling of the parts in the vicinity of the joint followed the reduction, and a well-marked globular ecchymosis indicated for several days the position occupied by the head of the humerus immediately below the middle and outer third of the clavicle. The limb was placed in a triangular bandage. On the following morning passive movements were commenced and cautiously increased day by day, the patient being exhorted to use great care in gradually resuming the usual movements of the joint and limb, which instructions he faithfully carried out until complete recovery resulted.

Bryant ${ }^{1}$ gives an illustration of this injury and says: "Subclavicular dislocations in which the head of the humerus rests below the clavicle on the sternal side of the

1 Practice of Surgery, fourth edition, 1884, vol, ii., p. 360. coracoid process are exceedingly rare. I have never seen a complete example." Lower down in the same paragraph he says : "The bulk of cases recorded as of the subclavicular kind are probably subcoracoid." Rose and Carless ${ }^{2}$ say : "The subclavicular variety is very uncommon and merely an exaggeration of the subcoracoid, the head of the humerus passes further inwards and lies deeply under the pectoralis major, on the second and third ribs." Keen and White," under the head of anterior dislocation, say : "These present two varieties, the subcoracoid and the intracoracoid, according to the distance to which the head of the humerus is displaced inwards. An extreme form of the latter is sometimes called the subclavicular."

Newark, Notts.

\section{adtervical Sorietirs.}

\section{ROYAL SOCIETY OF MEDICINE.}

\section{OBSTETRICAL AND GYNECOLOGICAL SECTION.}

Tuberculosis of the Fallopian Tube.-Casarean Hysterectomy. - Excretion of Creatinin. - Intra-uterine Death of the Fotus.

A MEETING of this section was held on April 9th, Dr. HerberT R. Spencer, the President, being in the chair.

Dr. H. MACNAUGHTON-JoNES read a short communication on the subject of Primary Unilateral Tuberculosis of the Fallopian Tube. He briefly reviewed the more recent etiological and histological points bearing on tuberculosis of the female genitalia, dealing with the relative frequency with which the various organs are affected from the vulva to the ovary. The occurrence of primary tuberculosis in any of the genitalia was not common but a unilateral primary tuberculosis was very rare. His communication dealt with primary unilateral tuberculosis of the Fallopian tube, of which he had met with two instances, and he had one case of primary tuberculosis of both tabes. In all these the rest of the genitalia were healthy. The details of the three cases were given and all the removed tubes were shown, together with the microscopical sections. In the case which was the source of this communication a tuberculous pyosalpinx was removed six and a half years ago. The patient had had one twin pregnancy and three other pregnancies since. He had recently to perform on this patient a coliotomy, 39 days after labour, for an extensive septic perimetritis (the section of the matted adnexa was shown with the epidiascope). There was no evidence of tubercle. She was now perfectly well. All the five children were strong and healthy. $\mathrm{Mr}$ J. H. Targett and Dr. Cuthbert Lockyer had made the reports. He (Dr. Macnaughton-Jones) had received replies from some 35 leading gynæcologists in the United Kingdom and abroad before bringing the case forward as to the records of such a condition. Only in seren of the home clinics were there records of such a lesion and in but three of the foreign.

Dr. KEDARNATH Das of Calcutta communicated a short paper on Three Cases of Cæsarean Hysterectomy for Atresia of the Vagina which was read by the honorary secretary. Traumatism during labour in which instruments were used was the cause of the condition in each case. Two of the cases were complicated with vesico-vaginal fistulæ which had resisted attempts to close them, although in one case a recto-vaginal fistula had been closed. In the first case the mother died, probably from the infection of the peritoneum through the vesico-vaginal fistula. In this case the child lived. In the second case the mother lived but a dead fœlus was removed from the uterus. In the third case both mother and child lived. Vesico-vaginal fistula was frequent in India. The occurrence of conception in such peculiar circumstances was worthy of note.

Dr. O. J. NEPEAN LONGRIDGE read a short communication on the Oreatinin Excretion of Lying-in Women during the most active period of involution of the uterus. The paper was based on 90 estimations of creatinin and 180 estimations of the total nitrogen in the urine. The patients were delivered in Queen Charlotte's Lying-in Hospital and were kept upon a creatinin-free diet during the time they were under observation. The endogenous creatinin alone was estimated.

2 Manual of Surgery, sixth edition, 1905, p. 627

American Text-book of Surgery, third edition, 1900, vol. i., p. 436. 